\title{
Direct observation of respectful maternity care in five countries: a cross-sectional study of health facilities in East and Southern Africa
}

Heather E. Rosen ${ }^{1 *}$, Pamela F. Lynam², Catherine Carr ${ }^{3}$, Veronica Reis ${ }^{4}$, Jim Ricca ${ }^{3}$, Eva S. Bazant ${ }^{3}$, Linda A. Bartlett ${ }^{1}$, on behalf of the Quality of Maternal and Newborn Care Study Group of the Maternal and Child Health Integrated Program

\begin{abstract}
Background: Poor quality of care at health facilities is a barrier to pregnant women and their families accessing skilled care. Increasing evidence from low resource countries suggests care women receive during labor and childbirth is sometimes rude, disrespectful, abusive, and not responsive to their needs. However, little is known about how frequently women experience these behaviors. This study is one of the first to report prevalence of respectful maternity care and disrespectful and abusive behavior at facilities in multiple low resource countries.

Methods: Structured, standardized clinical observation checklists were used to directly observe quality of care at facilities in five countries: Ethiopia, Kenya, Madagascar, Rwanda, and the United Republic of Tanzania. Respectful care was represented by 10 items describing actions the provider should take to ensure the client was informed and able to make choices about her care, and that her dignity and privacy were respected. For each country, percentage of women receiving these practices and delivery room privacy conditions were calculated. Clinical observers' open-ended comments were also analyzed to identify examples of disrespect and abuse.
\end{abstract}

Results: A total of 2164 labor and delivery observations were conducted at hospitals and health centers. Encouragingly, women overall were treated with dignity and in a supportive manner by providers, but many women experienced poor interactions with providers and were not well-informed about their care. Both physical and verbal abuse of women were observed during the study. The most frequently mentioned form of disrespect and abuse in the open-ended comments was abandonment and neglect.

Conclusions: Efforts to increase use of facility-based maternity care in low income countries are unlikely to achieve desired gains if there is no improvement in quality of care provided, especially elements of respectful care. This analysis identified insufficient communication and information sharing by providers as well as delays in care and abandonment of laboring women as deficiencies in respectful care. Failure to adopt a patient-centered approach and a lack of health system resources are contributing structural factors. Further research is needed to understand these barriers and develop effective interventions to promote respectful care in this context.

Keywords: Respectful maternity care, Quality of care, Disrespect, Maternal health, Ethiopia, Kenya, Madagascar, Rwanda, Tanzania, Zanzibar

\footnotetext{
* Correspondence: heather.e.rosen@gmail.com

'Johns Hopkins Bloomberg School of Public Health, Baltimore, MD, USA

Full list of author information is available at the end of the article
}

C Biomed Central
(C) 2015 Rosen et al. Open Access This article is distributed under the terms of the Creative Commons Attribution 4.0 International License (http://creativecommons.org/licenses/by/4.0/, which permits unrestricted use, distribution, and reproduction in any medium, provided you give appropriate credit to the original author(s) and the source, provide a link to the Creative Commons license, and indicate if changes were made. The Creative Commons Public Domain Dedication waiver (http://creativecommons.org/publicdomain/zero/1.0/) applies to the data made available in this article, unless otherwise stated. 


\section{Background}

Increasing access of pregnant women to skilled care during childbirth is a key strategy for reducing maternal and early neonatal mortality and morbidity. Most maternal deaths are considered preventable [1] and the majority could be averted by increased access to a skilled care provider supported by the resources of a functioning health system [2]. Recent modeling of the effect of scaling up selected evidence-based interventions during facility-based labor and delivery confirms a $79 \%$ decrease in maternal deaths is possible [3]. With the global agenda historically focused on increasing access, or quantity, of skilled care, the need to improve quality of care has received less attention $[4,5]$. To save women's lives and improve maternal and newborn health, women must both come to the facility to give birth with a skilled health provider and receive high quality care to prevent and address complications that may arise.

Quality of care encompasses structure, processes of care, and outcomes [6]. Structural elements include the presence of needed medicines, equipment, and provider training while outcomes are changes in health status and patient satisfaction. Processes of care include both technical aspects, which is the delivery of clinical procedures and treatments, and the client-provider interpersonal relationship including how information is shared and decisions about care are made [7]. The personal interaction between client and provider is important in shaping women's experiences and their perceptions of maternity care [8]. Poor interpersonal communication between client and provider during maternity care at health facilities in low resource settings is increasingly recognized as a barrier to accessing skilled care for routine and complicated births $[9,10]$. Women and their families especially mention rude and uncaring provider attitudes, lack of privacy, discrimination against cultural practices, physical abuse, dirty facilities, and delays in receiving care as reasons for dissatisfaction with facility services or for not giving birth at facilities nor seeking facility-based care for complications [11-16].

An increasingly cited framework for describing interpersonal aspects of care during childbirth is the seven domains of disrespect and abuse (D\&A) outlined in Bowser and Hill's landscape evidence review: physical abuse; non-consented care; non-confidential care; nondignified care; discrimination; abandonment of care; and detention in facilities [17]. The White Ribbon Alliance subsequently published the Respectful Maternity Care Charter: The Universal Rights of Childbearing Women, grounded in international human rights instruments such as the Universal Declaration of Human Rights [18]. The seven articles of the Charter are closely aligned to the seven domains of D\&A (see 'Seven rights') [19]. While these approaches are similar, the Charter frames the discussion in terms of positive, desired behaviors. The concept of respectful maternity care (RMC) acknowledges that women's experiences of childbirth are vital components of health care quality and that their "autonomy, dignity, feelings, choices, and preferences must be respected [19]." RMC has commonalities with other efforts to refocus medical care away from a disease-oriented model which privileges the physician as expert including patient-centered care and the humanization of childbirth $[20,21]$.

Seven rights of childbearing women from Respectful Maternity Care Charter [18].

Article 1. Every woman has the right to be free from harm and ill treatment.

Article 2. Every woman has the right to information, informed consent and refusal, and respect for her choices and preferences, including companionship during maternity care.

Article 3. Every woman has the right to privacy and confidentiality.

Article 4. Every woman has the right to be treated with dignity and respect.

Article 5. Every woman has the right to equality, freedom from discrimination, and equitable care. Article 6. Every woman has the right to healthcare and to the highest attainable level of health.

Article 7. Every woman has the right to liberty, autonomy, self-determination, and freedom from coercion.

There is limited evidence on the prevalence of respectful care or D\&A in facility-based maternity services delivered in low-resource settings [17, 22]. Neither routine health information systems nor facility assessments such as the Service Provision Assessment (SPA) capture this type of data [23]. Four recent studies in Kenya, Tanzania, Ethiopia, and Nigeria analyzed women's experiences during childbirth to estimate prevalence of disrespect and abuse ( $20 \%, 20-28 \%, 78$, and $98 \%$, respectively) [24-27]. Our team conducted a study of quality of care at health facilities in five countries in East and Southern Africa with a focus on clinical procedures for prevention, identification, and management of the most common causes of maternal and newborn mortality during childbirth. Although the study was not designed with a specific plan to assess respectful care or D\&A during labor and delivery, patientcentered care was one of the dimensions of quality evaluated. To meet the research gap, we applied the lens of women's rights and the Respectful Maternity Care Charter to relevant data in the quality of care study. The goal of this paper is to provide a descriptive overview of the quality of respectful maternity care in diverse facility settings in East and Southern Africa. 


\section{Methods}

\section{Study design, context, and sampling}

This is an analysis of select data from a series of cross-sectional surveys implemented in 2009-2012 by the Maternal and Child Health Integrated Program (MCHIP) to assess quality of care in Ethiopia, Kenya, Madagascar, Rwanda, and the United Republic of Tanzania. In each country, the study partnered with the Ministries of Health, MCHIP program offices, and other stakeholders. The overall objective of the study was to guide quality improvement activities for facility-based maternal and newborn care by determining the frequency and quality of key interventions through direct observation of care. Quality of care was defined based on globally accepted, evidence-based guidelines for maternal and newborn health from the World Health Organization's manual, Managing Complications in Pregnancy and Childbirth [28]. Patient-centered care is an element of these guidelines including provider-client interactions.

Details of the sampling strategy are summarized in Table 1 and reported elsewhere [29-37]. The study was designed to focus on high delivery volume facilities to ensure observers would be present for several deliveries during their visit to each facility. The Kenya survey was designed to be nationally representative with all facility levels represented. Hospitals and health centers throughout the country were also included in Rwanda. MCHIP was conducting (or preparing to conduct) activities to improve maternal and newborn health in all five countries at the time of the survey. In Tanzania, the survey was conducted as a baseline in facilities prior to the start of program activities. The survey in Tanzania was implemented and analyzed separately for the mainland and Zanzibar since they each have their own health systems.

\section{Data collection}

This paper presents data from the facility inventory survey tool and the labor and delivery observation checklist. The inventory included a complete review of facility infrastructure, presence of necessary equipment and medicines for routine and complicated deliveries, and services offered. Relevant to respectful care, the infrastructure section included a visit by data collectors to the delivery room(s) to determine the level of privacy afforded women. The labor and delivery checklist was a comprehensive tool to capture whether the provider correctly performed key evidenced-based interventions and was divided into four sections: initial client assessment, observation of labor, delivery, and postpartum. The checklist focused on clinical skills such as active management of the third stage of labor, essential newborn care practices, partograph use, and screening for complications.

Ten items concerning provider-client interactions were included in the observation tool; all described actions the provider might take. The five provider actions in initial client assessment were whether the provider greeted the client in a respectful manner, encouraged her to have a support person present, explained procedures before proceeding, informed client of findings, and asked if she had any questions. During observation of labor, the items were whether the provider explained what would happen during labor to the client, encouraged the client to consume food or fluids, encouraged or assisted the client to ambulate and assume different positions, supported the client in a friendly way, and draped the client.

At the end of a case, observers could enter open-ended comments about the quality of care they observed. During training, observers were instructed to use this space to record anything they felt was important in understanding or adding depth to the case, but was not covered in the checklists. If they observed practices that were not to standard, these would be noted in the comments section. No instructions specific to RMC or D\&A were given to observers.

Clinical observer training, the survey tools, and study procedures were standardized across countries, with practicing nurses, midwives, and doctors serving as observers.

Table 1 Summary of samples by country

\begin{tabular}{|c|c|c|c|}
\hline Country & Facility selection criteria & Number and type of facility & Geographic coverage \\
\hline Ethiopia & High delivery caseload ( $\geq 5)$ & 19 facilities; all hospitals & $\begin{array}{l}5 \text { of } 9 \text { regions plus Addis } \\
\text { Ababa and Dire Dawa }\end{array}$ \\
\hline Kenya & $\begin{array}{l}\text { Nationally representative by } \\
\text { facility type, region, and } \\
\text { managing authority }\end{array}$ & $\begin{array}{l}170 \text { facilities; } 142 \text { hospitals, } \\
28 \text { health centers/dispensaries }\end{array}$ & All \\
\hline Zanzibar & $\begin{array}{l}\text { High delivery caseload }(\geq 1) \\
\text { program facilities }\end{array}$ & 9 facilities; 5 hospitals, 4 health centers & All \\
\hline Rwanda & $\begin{array}{l}\text { Hospitals and randomly selected } \\
\text { health centers by region }\end{array}$ & 72 facilities; 42 hospitals, 30 health centers & All \\
\hline Madagascar & $\begin{array}{l}\text { High delivery caseload }(\geq 2) \text { and } \\
3 \text { program facilities }\end{array}$ & 36 facilities; 27 hospitals, 9 health centers & 17 of 22 regions \\
\hline Tanzania mainland & $\begin{array}{l}\text { High delivery caseload }(\geq 1) \\
\text { program facilities }\end{array}$ & $\begin{array}{l}52 \text { facilities; } 12 \text { hospitals, } 40 \text { health } \\
\text { centers/dispensaries }\end{array}$ & 12 of 25 mainland regions \\
\hline
\end{tabular}


Teams typically spent 2-3 days at each facility working two 8-h shifts per day. Observers followed all consenting clients in the maternity areas during their shift, unless there were too many concurrent clients or a complicated case was prioritized. Paper data collection forms were used in the first survey in Kenya; in following surveys, data were collected using basic smartphones with customdesigned software and built-in data checks. Efforts were made to minimize the effect of observation on provider behavior, i.e. the Hawthorne effect [38], by assuring providers that data collection was anonymous and individual performance would not be reported to their supervisors or shared publically (published reports only refer to aggregate data). Providers were not aware of what topics and items were on the checklists, so they could not prepare in any way. Observers did not visit facilities where they currently or previously worked as clinicians, to minimize the effect of personal and professional relationships.

\section{Analysis \\ Observational checklist and facility inventory}

The unit of analysis was an observation which represents a unique woman, but not a unique provider since providers usually cared for multiple women during the observation period. Data from the facility inventory was linked to individual observations at a given facility in order to present data on privacy by observation (as opposed to by facility). Frequency of occurrence of checklist items and privacy conditions, expressed as a percentage of observations, was calculated by country and for the entire study population. The highest and lowest country percentage for an item is presented as the range. Missing and "don't know" answers were excluded from calculations. Observers were trained to record a "don't know" response only in rare occurrences (for instance if they were away from the client during that time or they had trouble seeing what the provider was doing). The overall study was designed to provide descriptive data for multiple countries; differences in sampling strategy resulted in varying coverage of facilities within each country and cross-country statistical tests were not conducted (Table 1). Weighting was applied to data from the Kenya study where the study was designed to be nationally representative. Analysis was conducted using Stata 11 (StataCorp. 2009. Stata Statistical Software: Release 11. College Station, TX: StataCorp LP.).

\section{Open-ended comments}

Not all observations of labor and delivery care included open-ended comments. Those with comments were analyzed with a priori codes based on the seven articles of the Charter and the descriptions of these rights and their violations in an advocacy guide for the Charter $[18,19]$. Comments in French from Rwanda and Madagascar were translated into English for analysis. Based on the small number of events by category in each country, only aggregate data are presented here. Some observation comments mentioned multiple events, either of the same category or different categories. Number of unique observations with incidents in each of the categories and number of total incidents (differs only where multiple incidents in an observation) are reported. Comments that were particularly striking or summarized commonalities were selected as examples. Comments from the Kenya study were not available for analysis because the paper forms were misplaced.

\section{Ethical approval}

The Johns Hopkins Bloomberg School of Public Health Institution Review Board (IRB) reviewed the study and approved all protocols and consent forms. On a country basis, the study received approval from the Ethiopian Public Health Association IRB, Kenya Medical Research Institute Ethical Review Board, Ministry of Health Ethical Committee in Madagascar, Rwanda National Ethics Committee, Ethical Review Board of the Tanzania National Institute for Medical Research, and Zanzibar Medical Research and Ethics Committee. Informed consent was obtained from the facility director and all participating health providers prior to observation and all clients (or next of kin if necessary) prior to their participation in the study. All providers and clients were assigned id codes to protect their privacy.

\section{Results}

\section{Characteristics of observations}

The facility, provider, and client characteristics of the 2164 labor and delivery observations were very similar across countries (Table 2). Observations were conducted primarily at hospitals in all countries $(80 \%$ of deliveries or greater were at hospitals) except in the Tanzania mainland survey, which had a more even mix of facilities with health centers and dispensaries. Ethiopia's observations were in hospitals. The majority of observed births were conducted by nurses and midwives $(87 \%)$ who were female (87\%). In Ethiopia, doctors assisted $20 \%$ of clients and $19 \%$ were doctors in Madagascar. Medical and nursing students and unskilled assistants delivered services in $5 \%$ of observations.

Right to information, informed consent and refusal, and respect for her choices and preferences (Article 2)

The woman's right to information was assessed in four checklist items. At their initial consultation (usually admission in labor), providers explained procedures to the clients prior to actions in $62 \%$ of cases (range 38-77\%) (Table 3). Also during the initial examination, it was noted that providers shared their findings with clients in $67 \%$ of observations (range 41-76\%). Scores were 
Table 2 Distribution of labor and delivery observations by facility, provider, and client characteristics

\begin{tabular}{|c|c|c|c|c|c|c|c|}
\hline $\begin{array}{l}\text { Observation } \\
\text { characteristics }\end{array}$ & $\begin{array}{l}\text { Ethiopia } \\
(N=192)\end{array}$ & $\begin{array}{l}\text { Kenya } \\
(N=626)\end{array}$ & $\begin{array}{l}\text { Zanzibar } \\
(N=217)\end{array}$ & $\begin{array}{l}\text { Rwanda } \\
(N=293)\end{array}$ & $\begin{array}{l}\text { Madagascar } \\
(N=347)\end{array}$ & $\begin{array}{l}\text { Tanzania } \\
(N=489) \\
\end{array}$ & $\begin{array}{l}\text { Total } \\
(N=2164)\end{array}$ \\
\hline \multicolumn{8}{|l|}{ Health facility type } \\
\hline Hospital & $100.0 \%$ & $85.8 \%$ & $85.3 \%$ & $82.3 \%$ & $81.0 \%$ & $39.9 \%$ & $75.4 \%$ \\
\hline Health center/ dispensary & $0.0 \%$ & $14.2 \%$ & $14.7 \%$ & $17.7 \%$ & $19.0 \%$ & $60.1 \%$ & $24.6 \%$ \\
\hline \multicolumn{8}{|l|}{ Provider cadre ${ }^{1}$} \\
\hline Doctor & $20.3 \%$ & $1.1 \%$ & $0.5 \%$ & $2.0 \%$ & $18.7 \%$ & $2.5 \%$ & $6.0 \%$ \\
\hline Nurse/ midwife & $71.4 \%$ & $97.3 \%$ & $94.0 \%$ & $88.7 \%$ & $74.4 \%$ & $86.5 \%$ & $87.4 \%$ \\
\hline Student & $4.7 \%$ & $0.0 \%$ & $0.5 \%$ & $4.4 \%$ & $6.1 \%$ & $2.0 \%$ & $2.5 \%$ \\
\hline Unskilled & $0.0 \%$ & $1.6 \%$ & $1.8 \%$ & $0.7 \%$ & $0.3 \%$ & $8.4 \%$ & $2.7 \%$ \\
\hline Other/ missing & $3.6 \%$ & $0.0 \%$ & $3.2 \%$ & $4.1 \%$ & $0.6 \%$ & $0.6 \%$ & $1.4 \%$ \\
\hline \multicolumn{8}{|l|}{ Provider gender ${ }^{2}$} \\
\hline Male & $44.3 \%$ & $16.7 \%$ & $0.5 \%$ & $10.9 \%$ & $12.1 \%$ & $5.0 \%$ & $13.5 \%$ \\
\hline Female & $55.7 \%$ & $83.3 \%$ & $99.5 \%$ & $89.1 \%$ & $87.9 \%$ & $95.0 \%$ & $86.5 \%$ \\
\hline \multicolumn{8}{|l|}{ Client gravidity $^{3}$} \\
\hline Primigravida & & & $23.0 \%$ & $37.5 \%$ & $31.1 \%$ & $22.3 \%$ & $28.0 \%$ \\
\hline Multigravida & & & $77.0 \%$ & $62.5 \%$ & $68.9 \%$ & $77.7 \%$ & $72.0 \%$ \\
\hline
\end{tabular}

${ }_{1}^{1}$ Physician/resident includes: general practitioners, obstetricians, gynecologists, other specialists, residents; assistant medical officers in Tanzania and Zanzibar. Nurse/midwife includes: bachelor of science and diploma nurses, registered and enrolled nurses, bachelor of science and diploma midwives, registered and enrolled midwives, nurse/midwives; nursing officers and MCHA in Tanzania and Zanzibar; paramedics in Madagascar; health officers in Ethiopia. Student includes: medical and nursing students. Non-qualified staff includes: medical attendants, health assistants, and traditional birth attendants. Other/missing category in Kenya includes students

${ }^{2}$ Gender missing for 43 observations.

${ }^{3}$ Gravidity not collected in Ethiopia and Kenya, missing for 4 observations

similar by country for the two questions, with Kenya and Tanzania mainland having the highest percentages for both actions; clients in Ethiopia received this type of information from providers least often. Only in a third of observations, providers encouraged their clients to ask any questions (range 16-42\%) during this initial interaction. In the first stage of labor in $56 \%$ of observations, the provider explained to the woman what to expect during labor (range 38-62\%).

Three checklist items assessed whether providers promoted the woman's right to choose evidence-based, respectful, client-focused care practices. Women were encouraged to have a friend or relative with them for support in only 22 to $43 \%$ of cases for all surveys, except for Madagascar with a high of $67 \%$. More than half of women were assisted or encouraged to ambulate or assume alternative labor positions, except in Ethiopia. Encouragement to consume food and fluids differed greatly among surveys from $35 \%$ in Ethiopia to $80 \%$ in Tanzania.

\section{Right to privacy and confidentiality (Article 3 )}

Providers' use of drapes to preserve women's right to privacy was varied across surveys. Half or more of clients were draped in Rwanda and Madagascar while in other countries this was less common (24-47 \%). In surveys from Tanzania, Kenya, Madagascar, and Rwanda, more than half of women delivered in rooms with auditory and visual privacy $(54,65,72$, and $77 \%$ respectively). In Zanzibar and Ethiopia surveys, most women were in shared delivery rooms with no curtains to separate patients and no way to talk without being overheard (Fig. 1).

\section{Right to be treated with dignity and respect (Article 4)}

Two checklist items assessed provider's treatment of women with dignity and respect. When first meeting the client, women were offered a respectful greeting by their provider in $83 \%$ of observations (range 60-95\%). Women were supported in a friendly way by their provider during the first stage of labor in $86 \%$ of cases. All countries except Ethiopia scored $80 \%$ or higher on the item for friendly support.

\section{Characteristics of open-ended comments}

Clinical observer open-ended comments were available for analysis from Ethiopia, Madagascar, Rwanda, Tanzania mainland, and Zanzibar. These optional comments were added to $65 \%(n=996 / 1538)$ of observations. After excluding comments that were indecipherable or related only to survey technology $(n=30), 966$ observations with comments were available for analysis. Based on the Respectful Maternity Care Charter, 133 observations (14 \% of those with comments) described events which were likely violations of women's rights. Some cases included comments on multiple incidents relevant to an 
Table 3 Percent of observed clients with respectful maternity care practices

\begin{tabular}{|c|c|c|c|c|c|c|c|}
\hline Provider actions during initial assessment & $\begin{array}{l}\text { Ethiopia } \\
(N=110)\end{array}$ & $\begin{array}{l}\text { Kenya } \\
(N=442)\end{array}$ & $\begin{array}{l}\text { Zanzibar } \\
(N=116)\end{array}$ & $\begin{array}{l}\text { Rwanda } \\
(N=193)\end{array}$ & $\begin{array}{l}\text { Madagascar } \\
(N=277)\end{array}$ & $\begin{array}{l}\text { Tanzania } \\
(N=320)\end{array}$ & $\begin{array}{l}\text { Total } \\
(N=1458)\end{array}$ \\
\hline Greets client in a respectful manner & $59.8 \%$ & $78.2 \%$ & $88.3 \%$ & $76.0 \%$ & $88.8 \%$ & $94.6 \%$ & $82.9 \%$ \\
\hline Don't know or missing & 3 & 1 & 13 & 1 & 0 & 7 & 25 \\
\hline Encourages client to have support person & $33.6 \%$ & $38.4 \%$ & $22.1 \%$ & $42.6 \%$ & $66.5 \%$ & $39.5 \%$ & $43.1 \%$ \\
\hline Don't know or missing & 3 & 4 & 12 & 3 & 2 & 9 & 33 \\
\hline Explains procedures before proceeding & $37.7 \%$ & $77.0 \%$ & $65.0 \%$ & $40.4 \%$ & $49.1 \%$ & $72.1 \%$ & $61.9 \%$ \\
\hline Don't know or missing & 4 & 2 & 16 & 5 & 4 & 12 & 43 \\
\hline Informs client of findings & $40.6 \%$ & $76.2 \%$ & $66.0 \%$ & $56.4 \%$ & $67.8 \%$ & $69.0 \%$ & $67.0 \%$ \\
\hline Don't know or missing & 4 & 0 & 16 & 5 & 4 & 10 & 39 \\
\hline Asks client if she has any questions & $16.0 \%$ & $35.6 \%$ & $21.4 \%$ & $42.3 \%$ & $28.8 \%$ & $26.8 \%$ & $30.8 \%$ \\
\hline Don't know or missing & 4 & 7 & 13 & 4 & 3 & 10 & 41 \\
\hline Provider actions during labor & $\begin{array}{l}\text { Ethiopia } \\
(N=139)\end{array}$ & $\begin{array}{l}\text { Kenya } \\
(N=571)\end{array}$ & $\begin{array}{l}\text { Zanzibar } \\
(N=120)\end{array}$ & $\begin{array}{l}\text { Rwanda } \\
(N=244)\end{array}$ & $\begin{array}{l}\text { Madagascar } \\
(N=265)\end{array}$ & $\begin{array}{l}\text { Tanzania } \\
(N=306)\end{array}$ & $\begin{array}{l}\text { Total } \\
(N=1645)\end{array}$ \\
\hline Provider explains what will happen during labor to client & $37.9 \%$ & $61.9 \%$ & $44.8 \%$ & $58.4 \%$ & $53.8 \%$ & $60.0 \%$ & $56.4 \%$ \\
\hline Don't know or missing & 7 & 31 & 4 & 11 & 3 & 16 & 72 \\
\hline Provider encourages client to consume food and fluids during labor & $40.6 \%$ & $61.7 \%$ & $62.9 \%$ & $47.6 \%$ & $35.4 \%$ & $79.5 \%$ & $56.8 \%$ \\
\hline Don't know or missing & 6 & 49 & 4 & 11 & 2 & 14 & 86 \\
\hline $\begin{array}{l}\text { Provider encourages or assists client to ambulate and assume different } \\
\text { labor positions }\end{array}$ & $28.4 \%$ & $70.9 \%$ & $71.6 \%$ & $69.2 \%$ & $54.4 \%$ & $54.8 \%$ & $61.3 \%$ \\
\hline Don't know or missing & 5 & 48 & 4 & 10 & 2 & 16 & 85 \\
\hline Provider supports client in friendly way during labor & $66.2 \%$ & $87.1 \%$ & $90.5 \%$ & $91.6 \%$ & $79.5 \%$ & $93.2 \%$ & $86.1 \%$ \\
\hline Don't know or missing & 3 & 29 & 4 & 7 & 2 & 14 & 59 \\
\hline Provider drapes client before delivery & $44.9 \%$ & $24.2 \%$ & $47.4 \%$ & $68.4 \%$ & $85.9 \%$ & $46.1 \%$ & $48.5 \%$ \\
\hline Don't know or missing & 3 & 25 & 6 & 7 & 2 & 22 & 65 \\
\hline
\end{tabular}

article of the Charter or to multiple articles. A total of 151 events were identified from the 133 observations: there were 18 observations with two items. Table 4 shows the number of events and observations by Charter article.

\section{Right to be free from harm and ill treatment (Article 1)} Observers noted harmful treatment in 18 cases (3 with multiple aspects). These included two incidents of slapping or hitting the client (usually in connection to the client not complying with provider orders), for example from an observer in Tanzania: "patient came in second stage of labour pushing now and then, delivered, placenta had difficulties to remove as the mother was not torelant [sic] nurss [sic] slapped the woman." Multiple comments described use of fundal pressure, routine episiotomy, and the lack of anesthesia for episiotomies or suturing of tears. For example, an observer in Ethiopia recorded that providers at the facility "used episiotomies for all primi gravida mothers."

\section{Right to information, informed consent and refusal, and} respect for her choices and preferences (Article 2)

Comments on 18 observations related to this right including six times when providers failed to provide information. Within this category, other examples are when women were restricted in their choice of birth position and movement $(n=5)$ and not allowed fluids during labor $(n=2)$. This incident described by an observer in Rwanda (translated from French) demonstrates how a situation escalated to include other violations: Each time she had a contraction and wanted to give birth in a squatting position, two doctors intervened in vain to convince her to labor in the conventional position. They pressured her, even hit her so that she would accept to climb in the bed. In a case in Ethiopia, an observer reported that "no one provided components of mother frindly [sic] care, nothing had been informed regarding progress \& finding to the client."

\section{Right to privacy and confidentiality (Article 3)}

Eight comments were all related to lack of physical privacy during labor and delivery including a woman in Zanzibar "laying naked on the floor" and cases where there were no sheets or drapes for the mother.

Right to be treated with dignity and respect (Article 4) Seven comments related to this right noted unfriendly, disrespectful attitudes. During a case in Rwanda where the woman required surgery which was delayed waiting for appropriate staff and supplies, the observer noted the anesthetist yelling at 
a) Ethiopia ( $N=192)$

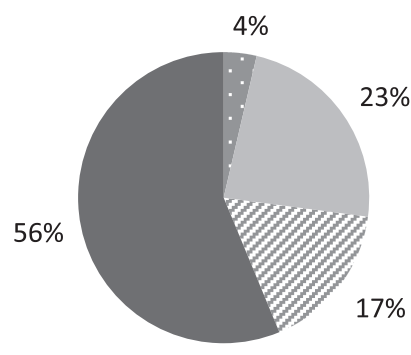

b) Kenya ( $\mathrm{N}=626)$

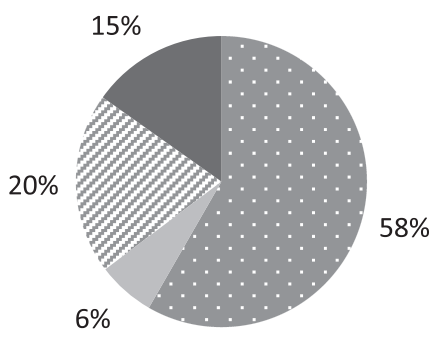

d) Rwanda ( $\mathrm{N}=\mathbf{2 7 9}$ )

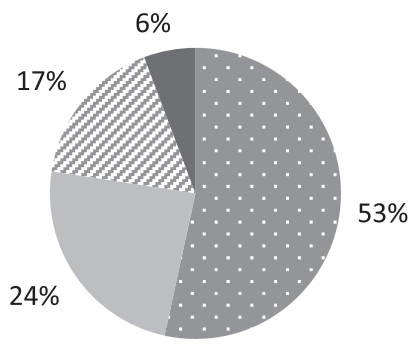

f) Tanzania ( $N=485)$

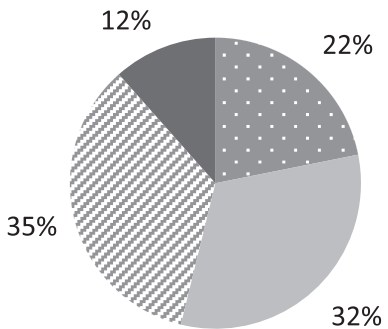

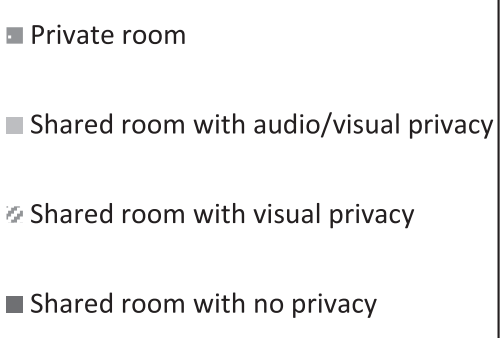

c) Zanzibar ( $\mathrm{N}=\mathbf{2 1 7})$

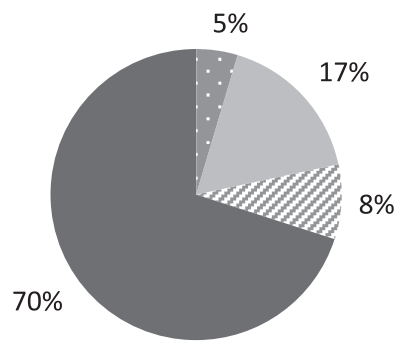

e) Madagascar ( $\mathrm{N}=337)$

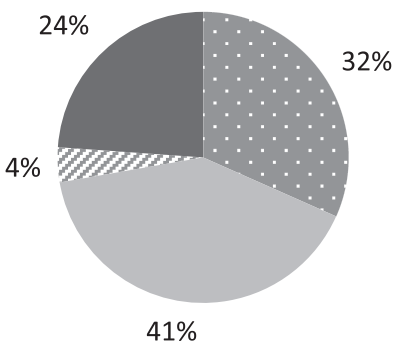

Fig. 1 Distribution of observed births according to elements of privacy ( $N=2164$ observations). *Ecludes 67 observations missing data

the woman in labor (translated). Soiled linens were being reused including where the provider was "[c]leaning the vagina with durty [sic] client clothes" (observer in Tanzania).

\section{Right to equality, freedom from discrimination, and} equitable care (Article 5)

Observers noted eight cases where client's access to necessary medications was affected by lack of finances. This resulted in denial and/or delays in receiving uterotonic for prevention of postpartum hemorrhage or augmentation of labor. From the comments, it is not clear in most cases whether the family was requested to pay for medications based on facility or national policy, lack of supplies, or as informal payments. In a ninth incident there was a woman in need of referral for complicated delivery who was not sent because of cost; luckily she and her baby were successfully treated at the facility (Madagascar). 
Table 4 Summary of violations of the Respectful Maternity Care Charter as reported in observer comments, by article of the Charter

\begin{tabular}{|c|c|c|}
\hline $\begin{array}{l}\text { Respectful } \\
\text { maternity } \\
\text { care rights }\end{array}$ & $\begin{array}{l}\text { Observations } \\
\text { with a violation }\end{array}$ & $\begin{array}{l}\text { Number } \\
\text { of violations }\end{array}$ \\
\hline $\begin{array}{l}\text { Article 1. Right to be free from harm } \\
\text { and ill treatment }\end{array}$ & 18 & 21 \\
\hline $\begin{array}{l}\text { Article 2. Right to information, informed } \\
\text { consent and refusal, and } \\
\text { respect for her choices and } \\
\text { preferences }\end{array}$ & 18 & 18 \\
\hline $\begin{array}{l}\text { Article } 3 \text {. Right to privacy and } \\
\text { confidentiality }\end{array}$ & 8 & 8 \\
\hline $\begin{array}{l}\text { Article 4. Right to be treated with } \\
\text { dignity and respect }\end{array}$ & 7 & 7 \\
\hline $\begin{array}{l}\text { Article 5. Right to equality, freedom } \\
\text { from discrimination, and } \\
\text { equitable care }\end{array}$ & 9 & 9 \\
\hline $\begin{array}{l}\text { Article 6. Right to healthcare and to } \\
\text { the highest attainable } \\
\text { level of health }\end{array}$ & 83 & 88 \\
\hline $\begin{array}{l}\text { Article 7. Right to liberty, autonomy, } \\
\text { self-determination, and freedom } \\
\text { from coercion }\end{array}$ & 0 & 0 \\
\hline Total all rights & $133^{\mathrm{a}}$ & 151 \\
\hline
\end{tabular}

${ }^{a}$ Total does not equal sum of number of observations for individual rights because some observations had multiple violations

Right to healthcare and to the highest attainable level of health (Article 6)

The most frequent violated right in open-ended comments was the right to care in 83 observations (five with multiple incidents). Of these 83 cases with abandonment or delays in care, a primary issue was clients who were monitored infrequently or not at all during labor and postpartum (28 cases). In eight cases, comments indicate that there were not enough providers or that a single provider was caring for multiple patients. Four women delivered without a provider and in two of these cases, the only provider was busy with another patient: "This woman delivered on her own. The midwife was attending another client" (observer in Zanzibar). There were many delays in decision-making reported - whether to perform a caesarean-section (CS) or assisted delivery, or whether to call another provider in for a consultation as well as delays in taking action, for instance waiting while other clients are attended, or for other providers to arrive. Comments related to some cases where the newborn did not survive suggest that neglect and delays in care were a contributing factor: "patient transferred from...health centre with prolonged labour and fetal distress...taken for CS after $3 \mathrm{~h} 15 \mathrm{mins}$. Baby noted to be fresh [stillbirth]...delays observed including decision to do elective CS before this case" (observer in Tanzania). Seven observations noted delays in starting resuscitation for an asphyxiated newborn; sometimes supplies were at another location, a specialist was needed, or the provider was delayed in identifying the need for resuscitation.

\section{Discussion}

This paper describes health provider care practices using the seven universal rights of childbearing women defined in the White Ribbon Alliance's Respectful Maternity Care Charter. This analysis is one of the first with a focus on measuring respectful care through direct observation of labor and delivery. Over two thousand observations were conducted in five countries using structured, standardized observation checklists based on World Health Organization guidelines. Due to the size and scope of the study, these results provide a broad overview of provider-client interactions in diverse settings in Sub-Saharan Africa. Encouragingly, women overall were treated with dignity and in a supportive manner by providers, but specific issues were identified that need to be addressed at the health systems level, including inadequate interpersonal communication by providers, abandonment and delays in care including a lack of routine monitoring, inadequate privacy protection, and in some cases, physical and verbal abuse.

Results from the observation checklist indicate that provider communication and information sharing skills were lacking during the study and prevented women from fully realizing their right to information, informed consent and refusal, and respect for their choices and preferences. Many women did not have procedures or the labor process explained to them and did not hear about the findings of exams. The least observed checklist item was whether the client was asked if she had any questions, with a prevalence of $16 \%$ in Ethiopia and high of only $42 \%$ in Rwanda. A provider who asks for questions (and listens to and answers them) is providing an important opening for the client to establish herself as an informed and active participant in the care process. In a study of D\&A in Ethiopia, women also reported a similar lack of client-provider information sharing: $63 \%$ of women were not encouraged to ask questions, $43 \%$ did not have procedures and the labor process explained, and $32 \%$ received no update on the progress of their labor [25].

As providers transition from a disease-oriented approach to a patient-centered one, they may need to build new interpersonal skills or improve existing ones. Educational interventions are an effective method of changing how providers communicate [39]. A Cochrane systematic review of training programs aimed at providers to improve patient-centered approach reported a positive effect on provider consultation skills [40]. However, no middle or low income countries were included, the providers were primarily specialists or context was a specific 
disease, and reported outcomes were heterogeneous (shared decision making, empathy, length of interview, etc.). Further research is needed understand whether these interventions are effective for improving interpersonal skills of maternal care providers in this context.

Observers' open-ended comments were a rich source of details, providing evidence of poor behaviors that were not explicitly asked in the checklist. Delays in care and abandonment of women during labor, delivery, and postpartum were the most frequent type of respectful maternity care rights violation noted in the comments (over $60 \%$ of cases that classified as violations). Reports of women feeling ignored and neglected during facility delivery are common in the literature [22]. Although definitions were variable, the four studies identified earlier as providing estimated prevalence of D\&A from Ethiopia, Nigeria, Kenya, and Tanzania reported neglect and abandonment in 9-29 \% of women [24-27]. Especially concerning in the present study were comments describing situations with the potential to become lifethreatening for mother and newborn. These include reported delays in referral or performing cesarean sections or newborn resuscitation and women delivering without the help of a provider. Nine percent of women in the Nigeria study and $4-5 \%$ of women in Tanzania reported delivering alone [26, 27].

Observer comments identified lack of resources, including staff shortages, as key reasons for abandonment and neglect. These five countries face severe staff shortages with the density of skilled health workers (midwives, nurses, and physicians) per 10,000 population far below the WHO threshold of 22.8 [41]. Basic infrastructure is also lacking; nationally representative surveys in Ethiopia, Kenya, Rwanda, and Tanzania reported no electricity available in $14,26,18$, and $50 \%$ of facilities, respectively [42]. The current study found that availability of essential supplies for deliveries at visited facilities was lacking (range $20-57 \%$ by country for presence of sterile scissors or blade, disposable cord ties or clamps, suction apparatus for use with catheter, and skin antiseptic) [30-35]. The important role of lack of resources as well as absence of accountability policies and facility culture in mistreatment of women at facilities was identified in a recent mixed methods systematic review [22].

Long term exposure of providers to intractable health system problems can lead to poor morale, compassion fatigue, and disrespectful treatment of clients and fellow providers [43-47]. There is a need to systematically examine how these constraints commonly found in low income countries foment D\&A and act as a barrier to respectful care. This research should inform efforts to reorganize care and put in place plans to encourage respectful care at the health systems level. For example, support for respectful care could be achieved by improvements in facility infrastructure for privacy and to provide dedicated space in the delivery room for birth companions. Since this is a developing area, few relevant interventions have been developed or tested. Some of the strategies suggested for interventions include greater health systems accountability, policy and regulatory approaches, training and supportive supervision, ethical codes of conduct, and community-level awareness programs for women $[45,48,49]$. Standards-Based Management and Recognition (SBM-R), which uses detailed performance standards to assess health facilities as part of a change management strategy for improvement, has demonstrated positive impacts on maternal newborn care quality and also may be a useful approach for respectful care [50].

A particular concern for those conducting research on RMC and D\&A is how to determine which events or situations qualify as respectful or abusive. An outsider seeing women giving birth two to a bed may find this situation unacceptable, but local providers and clients may view this as part of the typical experience. Our approach in the present analysis was to use the standards in the Respectful Maternity Care Charter because the overall Quality of Care study was based on international standards. Freedman et al. proposed a research definition of D\&A to include interactions and facility conditions that local consensus considers D\&A or that women experience as D\&A [51]. As awareness and norms change over time, they expect the definition to expand to include human rights standards. These two approaches can yield different results since some items identified here as negative behaviors by international norms may not have been seen as disrespectful in the local context, by women experiencing them, or by their providers.

\section{Limitations}

A limitation of the study is that the data collection tool was not designed specifically to examine RMC. There were no checklist items related to respectful care during the second and third stage of labor or postpartum and certain concepts such as consent for procedures and detention of mothers were not covered at all. Regarding the open-ended comments, the results should be interpreted carefully since observers were not specifically trained or sensitized to the concept of respectful care and the decision whether to enter a comment for a given observation was at their own discretion. Since our observers were health providers, the comments were also likely influenced by their professional training and experiences. Future research should consider incorporating comments as a fixed element with appropriate training on standards. Revised checklists with specific questions on delays/abandonment and other issues suggested from the analysis would also be useful. 
The overall study was designed to provide descriptive data and collected limited data on characteristics of facility, provider, and client. Concurrent activities to improve maternal and newborn health were likely taking place in the survey countries before and during the survey and these may have impacted results. In addition, the facility sample in each country varied considerably in terms of regional coverage and level and size of facilities and thus should not necessarily be considered generalizable to the entire country. Differences between countries may reflect the sampling strategy, or other unmeasured factors rather than true differences. Where possible, future research should utilize a sampling strategy that better represents coverage of facilities of certain types and facilitates comparisons. Research that explores associations between facility, provider and client-level factors and the observed elements of respectful maternity care, or lack of it, would be valuable. Lastly, we cannot ignore the possible impact of observation on provider behavior (Hawthorne effect), although efforts were made to minimize its impact. This may have caused an underestimate the true extent of the issues explored here.

\section{Conclusions}

Efforts to increase use of facility-based maternity care in low income countries are unlikely to achieve the desired gains if there is no improvement in quality of care provided, especially elements of respectful care. This analysis identified insufficient communication and information sharing by providers as well as delays in care and abandonment of laboring women as deficiencies in respectful care. Failure to adopt a patient-centered approach and a lack of health system resources are contributing structural factors. Further research is needed to understand these barriers and develop effective interventions to promote respectful care in this context.

\section{Competing interests}

The authors have no conflict of interest.

\section{Authors' contributions}

All authors contributed to the overall design and acquisition of data for the study. HER conducted the analysis and wrote the manuscript. PFL and ESB contributed to the interpretation of the data and helped to draft the manuscript. CC, VR, JR, and $L A B$ made critical revisions to the manuscript. All authors read and approved the final manuscript.

\section{Acknowledgements}

We wish to thank the Ministry of Health in Ethiopia, Kenya, Madagascar, Rwanda, the United Republic of Tanzania, and Zanzibar for their support. Thank you to the data collectors, facility directors, health providers, and clients in all of the countries who participated in the study. We are especially grateful for the contributions of local MCHIP and Jhpiego staff in all of the countries. Additional thanks to Kate Brickson, Susan Moffson, and Mary Ross Burner for their support during manuscript preparation.

The Quality of Maternal and Newborn Care Study Group of the Maternal and Child Integrated Program comprises (in alphabetical order): Gloriose Abayisenga, Paul Ametepi, David Cantor, Leonardo Chavane, Sheena Currie, Joseph de Graft-Johnson, Mary Drake, Ashebir Getachew, Patricia Gomez, Frank Kagema, Christina Lulu Makene, Isaac Malonza, Gathari Ndirangu, Marya
Plotkin, Barbara Rawlins, Jean Pierre Rakotovao, Gaudiosa Tibaijuka, Alemnesh Tekleberhan, Maria da Luz Vaz, and Jeremie Zoungrana.

This study was funded by the United States Agency for International Development under the terms of the Leader with Associates Cooperative Agreement GHS-A-00-08-00002-000.

\section{Author details}

${ }^{1} J$ ohns Hopkins Bloomberg School of Public Health, Baltimore, MD, USA.

${ }^{2}$ Jhpiego/Kenya, Nairobi, Kenya. ${ }^{3}$ Jhpiego/Baltimore, Baltimore, MD, USA.

${ }^{4}$ Jhpiego/Mozambique, Maputo, Mozambique.

Received: 9 September 2014 Accepted: 31 October 2015

Published online: 23 November 2015

\section{References}

1. Souza JP, Tunçalp Ö, Vogel JP, Bohren M, Widmer M, Oladapo OT, et al. Obstetric transition: the pathway towards ending preventable maternal deaths. BJOG. 2014;121:1-4

2. World Health Organization. Maternal mortality: helping women off the road to death. WHO Chron. 1986:40(5):175-83.

3. Bartlett L, Weissman E, Gubin R, Patton-Molitors R, Friberg IK. The impact and cost of scaling up midwifery and obstetrics in 58 low- and middle-income countries. PLoS One. 2014;9(6):e98550.

4. van den Broek NR, Graham WJ. Quality of care for maternal and newborn health: the neglected agenda. BJOG. 2009;116 Suppl 1:18-21.

5. Hodgins S. What happens after women come through the door? Glob Health. 2011;Spring 2011(10):12.

6. Donabedian A. Evaluating the quality of medical care 1966. Milbank Q. 2005;83(4):691-729.

7. Donabedian A. The quality of care. How can it be assessed? JAMA 1988;260(12):1743-8

8. World Health Organization. People at the centre of health care: harmonizing mind and body, people and systems. Geneva: World Health Organization; 2007.

9. Nair M, Yoshida S, Lambrechts T, Boschi-Pinto C, Bose K, Mason EM, et al. Facilitators and barriers to quality of care in maternal, newborn and child health: a global situational analysis through metareview. BMJ open. 2014:4(5):e004749.

10. Knight HE, Self A, Kennedy SH. Why are women dying when they reach hospital on time? A systematic review of the 'third delay'. PLoS One. 2013;8(5):e63846.

11. Gabrysch S, Campbell OM. Still too far to walk: literature review of the determinants of delivery service use. BMC Pregnancy Childbirth. 2009;9:34.

12. Gebrehiwot T, Goicolea I, Edin K, San Sebastian M. Making pragmatic choices: women's experiences of delivery care in Northern Ethiopia. BMC Pregnancy Childbirth. 2012;12:113.

13. Mselle LT, Moland KM, Mvungi A, Evjen-Olsen B, Kohi TW. Why give birth in health facility? Users' and providers' accounts of poor quality of birth care in Tanzania. BMC Health Serv Res. 2013;13:174.

14. Shiferaw S, Spigt M, Godefrooij M, Melkamu Y, Tekie M. Why do women prefer home births in Ethiopia? BMC Pregnancy Childbirth. 2013:13:5.

15. Kruk ME, Paczkowski M, Mbaruku G, de Pinho H, Galea S. Women's preferences for place of delivery in rural Tanzania: a population-based discrete choice experiment. Am J Public Health. 2009;99(9):1666-72.

16. Bohren MA, Hunter EC, Munthe-Kaas HM, Souza JP, Vogel JP, Gulmezoglu AM Facilitators and barriers to facility-based delivery in low- and middle-income countries: a qualitative evidence synthesis. Reprod Health. 2014;11(1):71.

17. Bowser D, Hill K. Exploring evidence for disrespect and abuse in facility-based childbirth: report of a landscape analysis. Boston, MA: URC-Traction Project, Harvard School of Public Health; 2010.

18. White Ribbon Alliance. Respectful maternity care charter. Washington, DC: White Ribbon Alliance; 2011.

19. Windau-Melmer T. A guide for advocating for respectful maternity care. Washington, DC: Futures Group, Health Policy Project; 2013.

20. Rattner D. Humanizing childbirth care: a brief theoretical framework. Tempus Actas de Saúde Coletiva. 2010;4(4):41-8.

21. Institute of Medicine (U.S.). Committee on Quality of Health Care in America. Crossing the quality chasm : a new health system for the 21st century. Washington, D.C.: National Academy Press; 2001.

22. Bohren MA, Vogel JP, Hunter EC, Lutsiv O, Makh SK, Souza JP, et al. The mistreatment of women during childbirth in health facilities globally: a mixed-methods systematic review. PLoS Med. 2015;e1001847(6). 
23. DHS M. SPA questionnaires. Washington, DC: Measure DHS; 2012 [Available at: http://dhsprogram.com/What-We-Do/Survey-Types/SPA-Questionnaires.cfm] [Accessed: 6/22/14].

24. Abuya T, Warren CE, Miller N, Njuki R, Ndwiga C, Maranga A, et al. Exploring the prevalence of disrespect and abuse during childbirth in Kenya. PLoS One. 2015;10(4):e0123606

25. Asefa A, Bekele D. Status of respectful and non-abusive care during facility-based childbirth in a hospital and health centers in Addis Ababa, Ethiopia. Reprod Health. 2015;12(1):33.

26. Kruk ME, Kujawski S, Mbaruku G, Ramsey K, Moyo W, Freedman LP: Disrespectful and abusive treatment during facility delivery in Tanzania: a facility and community survey. Health Policy Plan. 2014.

27. Okafor II, Ugwu EO, Obi SN. Disrespect and abuse during facility-based childbirth in a low-income country. Int J Gynaecol Obstet. 2015;128(2):110-3.

28. World Health Organization. Dept. of Reproductive Health and Research., United Nations Population Fund., UNICEF., World Bank. Managing complications in pregnancy and childbirth: a guide for midwives and doctors. Geneva: World Health Organization; 2007.

29. Bazant E, Rakotovao JP, Rasolofomanana JR, Tripathi V, Gomez P, Favero R, et al. Quality of care to prevent and treat postpartum hemorrhage and preeclampsia/eclampsia : an observational assessment in Madagascar's hospitals. Med Sante Trop. 2013;23(2):168-75.

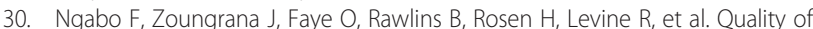
care for prevention and management of common maternal and newborn complications findings from a national health facility survey in Rwanda. Baltimore: Jhpiego; 2012.

31. Plotkin M, Tibaijuka G, Makene CL, Currie S, Maryjane L. Quality of care for prevention and management of common maternal and newborn complications: a study of 12 regions in Tanzania. Baltimore: Jhpiego; 2011.

32. Getachew A, Ricca J, Cantor D, Rawlins B, Rosen H, Tekleberhan A, et al. Quality of care for prevention and management of common maternal and newborn complications: a study of Ethiopia's hospitals. Baltimore: Jhpiego; 2011.

33. Kagema F, Ricca J, Rawlins B, Rosen H, Mukhwana W, Lynam P, et al. Quality of care for prevention and management of common maternal and newborn complications: findings from a National Health Facility Survey in Kenya-are services provided according to international standards? Baltimore: Jhpiego; 2011

34. Rasolofomanana JR, Rakotovao JP, Bazant E, Vandana T. Quality of care of the prevention and management of common maternal and newborn complications in health facilities in Madagascar. Baltimore: Jhpiego; 2011.

35. Plotkin M, Makene CL, Asma RK, Currie S, Tibaijuka G, Lacoste M, et al. Quality of maternal and newborn health services in Zanzibar, 2010 findings from selected health facilities in Unguja and Pemba. Baltimore: Jhpiego; 2012.

36. Makene C, Plotkin M, Currie S, Bishanga D, Ugwi P, Louis $H$, et al. Improvements in newborn care and newborn resuscitation following a quality improvement program at scale: results from a before and after study in Tanzania. BMC Pregnancy Childbirth. 2014;14(1):381.

37. Tripathi V, Stanton C, Strobino D, Bartlett L. Development and validation of an index to measure the quality of facility-based labor and delivery care processes in Sub-Saharan Africa. PLoS One. 2015;10(6):e0129491.

38. Mayo E. The human problems of an industrial civilization. New York, NY: Macmillan; 1933

39. Davis DA, Thomson MA, Oxman AD, Haynes RB. Changing physician performance. A systematic review of the effect of continuing medical education strategies. JAMA. 1995;274(9):700-5.

40. Dwamena F, Holmes-Rovner M, Gaulden CM, Jorgenson S, Sadigh G, Sikorskii A, et al. Interventions for providers to promote a patient-centred approach in clinical consultations. Cochrane Database Syst Rev. 2012;12:CD003267

41. Campbell J, Dussault G, Buchan J, Pozo-Martin F, Guerra Arias M, Leone C, et al. A universal truth: no health without a workforce. Geneva: Global Health Workforce Alliance and World Health Organization; 2013.

42. Adair-Rohani H, Zukor K, Bonjour S, Wilburn S, Kuesel AC, Hebert R, et al. Limited electricity access in health facilities of sub-Saharan Africa: a systematic review of data on electricity access, sources, and reliability. Glob Health Sci Pract. 2013;1(2):249-61.

43. Leape LL, Shore MF, Dienstag JL, Mayer RJ, Edgman-Levitan S, Meyer GS, et al. Perspective: a culture of respect, part 1: the nature and causes of disrespectful behavior by physicians. Acad Med. 2012;87(7):845-52.

44. Prytherch H, Kakoko DC, Leshabari MT, Sauerborn R, Marx M. Maternal and newborn healthcare providers in rural Tanzania: in-depth interviews exploring influences on motivation, performance and job satisfaction. Rural Remote Health. 2012:12:2072

45. USAID. Ending preventable maternal mortality: USAID maternal health vision for action, evidence for strategic approaches. Washington, DC: USAID; 2015.

46. Freedman LP, Kruk ME. Disrespect and abuse of women in childbirth: challenging the global quality and accountability agendas. Lancet. 2014;384(9948):e42-44.

47. Jewkes R, Abrahams N, Mvo Z. Why do nurses abuse patients? Reflections from South African obstetric services. Soc Sci Med. 1998;47(11):1781-95.

48. Leape LL, Shore MF, Dienstag JL, Mayer RJ, Edgman-Levitan S, Meyer GS, et al. Perspective: a culture of respect, part 2: creating a culture of respect. Acad Med. 2012;87(7):853-8.

49. World Health Organization. The prevention and elimination of disrespect and abuse during facility-based childbirth: WHO statement. Geneva: WHO; 2014.

50. Necochea E, Tripathi V, Kim YM, Akram N, Hyjazi Y, da Luz VM, et al. Implementation of the Standards-Based Management and Recognition approach to quality improvement in maternal, newborn, and child health programs in low-resource countries. Int J Gynaecol Obstet. 2015;130 Suppl 2:S17-24.

51. Freedman LP, Ramsey K, Abuya $T$, Bellows B, Ndwiga C, Warren CE, et al. Defining disrespect and abuse of women in childbirth: a research, policy and rights agenda. Bull World Health Organ. 2014;92(12):915-7.

\section{Submit your next manuscript to BioMed Central and take full advantage of:}

- Convenient online submission

- Thorough peer review

- No space constraints or color figure charges

- Immediate publication on acceptance

- Inclusion in PubMed, CAS, Scopus and Google Scholar

- Research which is freely available for redistribution

Submit your manuscript at www.biomedcentral.com/submit 